\title{
Taking the Pulse of COVID-19 in Higher Education: Are Students Satisfied with the Experience of Online Learning?
}

\author{
Xiufeng Xing ${ }^{1, *}$, Xueying Zhang ${ }^{1, \#}$, Mengfan $\mathrm{Xu}^{1, \#}$, Aiqin Xi ${ }^{1, \#}$, Xuli Zhao ${ }^{2}$ and
}

\author{
Fenghua Ren ${ }^{3}$
}

\author{
${ }^{1}$ School of Business, Qingdao University of Technology, Qingdao 266525, China \\ ${ }^{2}$ Office of Teaching Affairs, Qingdao University of Technology, Qingdao 266525, China \\ ${ }^{3}$ School of Information and Control Engineering, Qingdao University of Technology, Qingdao 266525, China \\ *Corresponding author. Email: xxfqd@126.com \\ \#These authors contribute equally to this article and should be considered co-first authors.
}

\begin{abstract}
This paper investigates the impact of COVID-19 on higher education. A pilot online survey followed by a course test and one field survey has been conducted sequentially in Chinese universities. The results of this exploratory research reveal that (1) more than half of respondents argue that online and traditional teaching pattern does make a difference in terms of teaching quality, and only a few students prefer virtual classroom to traditional classroom; (2) real data highlights that the pandemic has a critical impact on Chinese student grade via distance learning; and (3) only 49.33 percent students are satisfied with the experience of using virtual classroom during the earlier stage of the pandemic. The results are of particular interest to classroom teachers as well as administrators of higher education institutions under the ongoing COVID-19 pandemic. Keywords: e-learning, teaching quality, reliability and validity, Likert scale, COVID-19
\end{abstract}

\section{INTRODUCTION}

The nature of virtual classroom was the computer-based communication systems to assist scattered communities of active learners, and also as a kind of teaching and learning environment which was located within a computermediated communication system. In essence, the virtual classroom is real rather than imaginary so that the process of learning is integrated with the real world [1]. Since the concept of virtual classroom was put forward, over 19000 students across the world had applied virtual classroom to learn and cooperate through the internet for the period from 1996 to 2000. As technology advances, synchronous technologies enable the real time interactions between lecturers and students. Synchronous virtual classroom is commonly known as web-conferencing systems [2]. These systems make real time communications happen where multiple users simultaneously interact with each other through the internet. For instance, synchronous virtual classroom enhance interactivity and construct a sense of community in online and blended courses[3-4] discovered the use of synchronous online environments could facilitate students to learn from anywhere, without physically travelling to the traditional classroom. Additionally, virtual classroom platform enables students and instructors to interact with each other synchronously using features such as audio, video, text chat, application sharing and interactive whiteboard. There are presently various forms of virtual classrooms such as Google Classroom, Tencent Meeting and Zoom which are prevalent in higher education.

To date, the COVID-19 pandemic has been basically under control across China even though there is sporadic local epidemic. The pandemic has substantially affected almost all walks of life in the globe. According to Worldmeter just-in-time data, as of 20 September 2021, the total of confirmed cases was 229254684, and total death toll reached 4704813 high. The daily new increase was 510372 cases, and 7029 new daily death. As an effective countermeasure, the general public on Chinese mainland can apply for free vaccination as long as one is eligible for it. Chinese students of all levels have returned to normal since last September. However, in the spring of 2020, almost all students across the globe were forced to continue their study process via virtual classroom (VC).

This research aims to explore Chinese students' experience of using $\mathrm{VC}$ or online learning and the outcomes associated with online learning.

The remainder of the paper proceeds as follows: Section two describes the methodology used which includes research designs and data collection and analysis. Section three discusses the methodology used. The reliability and validity evaluation is done by Stata is also in section two. The empirical results are reported in Section three and Section four concludes the paper. 


\section{METHODOLOGY}

\subsection{Research Design}

The research consists of two surveys and one final exam. The online survey (survey 1 ) followed by a course exam at the end of the spring term of 2020 and one field survey (survey 2) in March 2021 have been conducted in sequence. Both surveys were anonymous.

Survey 1 contained six closed questions exclusive of respondent demographic information:

Q1. "Given the alternatives between computer and smartphone, which one do you prefer to complete your distance learning in your case?" and answer options (circle the answer): "smartphone"; "computer".

Q2. "What types of learning software do you choose to conduct your course online learning (Multiple-choice: "DingDing"; "Rain Classroom"; "QQ Classroom"; "Tencent Classroom"; "Wisdom Tree" ; "Other")?"

Q3. "Does the number of online participants or class size impact your learning effect ("little impact"; "somewhat impact"; "great impact")?"

Q4. "What is your favourite learning mode ("virtual classroom"; "traditional classroom"; "hybrid virtual/traditional classroom")?"

Q5. "What are the outstanding problems concerning online learning (Multiple-choice: "lack of effective interactions among teacher and students"; "poor internet connectivity"; "noise interference during class")?"

Q6. "Compared to traditional classroom, is there a big difference in teaching quality given the same instructor ("little difference"; "somewhat difference"; "great difference")?"

Regarding the course final test, it was launched online and applied the open-book approach because of COVID-19.

survey 2 was conducted in class in Business School of Qingdao University of Technology (QUT) in China. Survey 2 aims to investigate students' learning experience of VC during COVID-19. The paper questionnaire using five-point Likert scale technology was sent to two classes of 150 students who selected microeconomics course opened to all majors across QUT. Survey 2 contained 10 closed questions regarding the experience of $\mathrm{VC}$ in the spring term of 2020:

(1) VC facilitates one to access materials such as electronical books, PPTs and exercises synchronically as long as the materials being uploaded by teachers or instructors.

(2) VC facilitates one to get regular updates about the class.

(3) VC facilitates one to easily contact course teacher.

(4) VC facilitates one to learn through various modes such as recorded course, videos, audios etc.

(5) VC facilitates one to share ideas with peers.

(6) VC enhances communication among students in class.

(7) $\mathrm{VC}$ is helpful for teachers to give online lectures.

(8) VC is useful for hosting online exams.
(9) VC is useful for online assignment submission and grading.

(10) Overall, you are satisfied with VC given the COVID19 context.

Underline one answer for each of the above 10 questions from options: "Strongly agree (SA)"; "Agree (A)", "Neutral (N)"; "Disagree (DSA)" and "Disagree (DA)".Besides, survey 2 also contains respondents' information such as the way of returning to university for new semester, the rank of risk level (low risk, medium risk or high risk) of each respondent's residential area or community from which he or she came from and whether the nucleic acid test had been done according to the risk rank of corresponding area.

\subsection{Data Collection}

Survey 1 is created to explore the key aspects of the VC during the process of distance learning when the crisis was not under effective control in China. A total of 689 valid questionnaires were collected.

Following survey 1, about 3 months later, the final test of microeconomics in the form of open-book was launched on July 22, 2020, with a total of 794 students enrolled the test. The grade distribution associated with the test is displayed in Figure 1. In general, the mean of the grades is smaller than 65 , which is much lower than the one before the outbreak of COVID-19 pandemic.

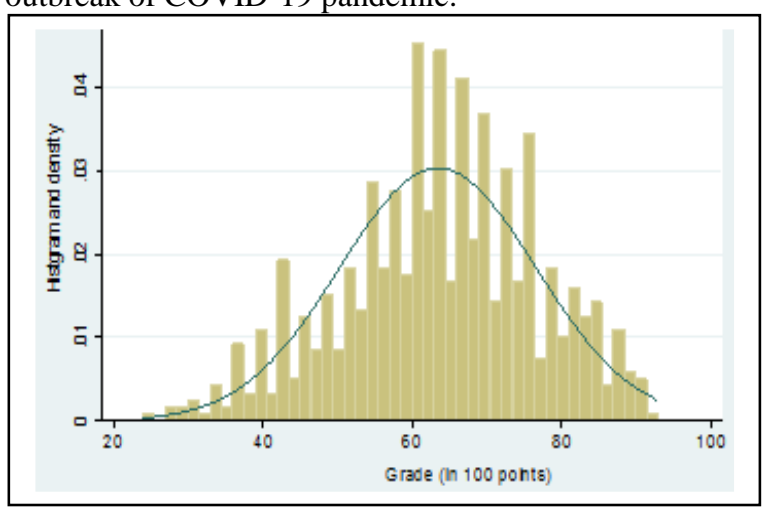

Figure 1. Student grade distribution from full sample.

\subsection{Reliability and validity test}

The reliability and validity tests for both surveys have been accomplished by using Stata software. As for survey 1 , although the value of cronbach's alpha is less than 0.60 , it is still meaningful since question 4 and 7 both have more than 1 option to choose, the commonly used reliability test is not applicable in this circumstance. Similarly, the validity test is barely passed as per the de facto standard. Regarding survey 2 which is designed and analyzed with the five-point Likert technology[5], the value of cronbach's alpha, namely the scale reliability coefficient is 0.8235 , thus accomplish the recommended value of 0.80 given 10 questions in the questionnaire. In the meanwhile, the 
validity test is passed in lieu of the de facto standard. The matrix concerning the validity test of survey 2 is as shown in Table 1 below.

Table 1. Validity Test Matrix of VC Experience

\begin{tabular}{|c|c|c|c|c|c|}
\hline & SA & A & N & DA & SDA \\
\hline SA & 1.0000 & & & & \\
\hline A & 0.7622 & 1.0000 & & & \\
\hline N & -.8632 & -0.9113 & 1.0000 & & \\
\hline DA & -.7792 & -0.9692 & 0.9416 & 1.0000 & \\
\hline SDA & -.7034 & -0.8246 & 0.8620 & 0.8916 & 1.0000 \\
\hline
\end{tabular}

a. "Strongly agree (SA)"; "Agree $(A)$ "; "Neutral $(N)$ ";,"Disagree $(D A)$ "; "Strongly Disagree

\section{RESULTS AND DISCUSSION}

This research finds that VC has a negative impact on Chinese students' experience and performance associated with using VC during the early stage of the epidemic.

Regarding survey 1 , it showcased that there were some major problems such as poor internet connectivity, less interaction between teacher and students and noise interruption during class. Particularly, survey 1 reveals that VC does affect teaching quality during the COVID-19 period, at least in our case.

As to course final test score which is shown in Figure 1, students' performance with VC is less desirable when compared to those before the outbreak of the pandemic.

With regard to survey 2 , as Table 2 revealed, the first item indicates that approximately 67 percent respondents agree that the virtual classroom facilitate one to access the learning materials, while about 7 percent respondents disagree with the statement, the remaining 26 percent of the respondents keep neutral. Regarding the second question, on the order of 69 percent students agreed with it, around 23 percent kept neutral, and the remaining 9 percent participants disagree with the statement. Concerning the third item, those who agree that the virtual classroom facilitates one to contact the instructor accounts for 62.67 percent, 27.33 percent of the participants remain neutral, while the remaining 10 percent disagree with the statement. Relating to the fourth question, 84 percent participants agree that virtual classroom help facilitate one to learn via various modes such as recorded course, videos and audios; while 2.67 percent disagree with the opinion, the rest 13.33 percent remain neutral. With respect to question five, the proportions of agree, neutral and disagree are $32.67 \%$, $41.33 \%$ and $26 \%$, respectively. Concerning the sixth item, only $21.33 \%$ subjects agree that VC facilitate students' communication, while $39.33 \%$ disagree with it. On the seventh item, $35.67 \%$ respondents agree with the statement, while $4 \%$ disagree. Regarding question eight, $82.67 \%$ of the participants agree that $\mathrm{VC}$ is useful for hosting online exams. When it comes to the ninth question, $56 \%$ of respondents agree with the statement that VC is helpful for online submission and grading, $27.33 \%$ remain neutral, while the rest $16.66 \%$ disagree with it. in item ten of the overall satisfaction with VC, only $5.33 \%$ respondents strongly agreed, $44 \%$ agreed, while $2.67 \%$ strongly disagreed; in other words, most students are not satisfied with the experience of VC.

Table 2. Descriptions of Student VC Experience $(\mathrm{N}=150)$

\begin{tabular}{|c|cc|ccc|cc|}
\hline \multirow{2}{*}{ Items } & \multicolumn{3}{|c|}{ SA $^{\mathbf{a}}$} & \multicolumn{3}{|c|}{$\mathbf{A}^{\mathbf{a}}$} & \multicolumn{2}{c|}{$\mathbf{N}^{\mathbf{a}}$} \\
\cline { 2 - 8 } & \multicolumn{2}{|c|}{ Count } & \% & \multicolumn{2}{|c|}{ Count } & \% & \multicolumn{2}{c|}{ Count } & \% \\
\hline$(1)$ & 12 & 8 & 89 & 59.33 & 39 & 26 \\
\hline$(2)$ & 18 & 12 & 85 & 56.67 & 34 & 22.67 \\
\hline$(3)$ & 15 & 10 & 79 & 52.67 & 41 & 27.33 \\
\hline$(4)$ & 37 & 24.67 & 89 & 59.33 & 20 & 13.33 \\
\hline$(5)$ & 13 & 8.67 & 36 & 24 & 62 & 41.33 \\
\hline$(6)$ & 6 & 4 & 26 & 17.33 & 59 & 39.33 \\
\hline$(7)$ & 21 & 14 & 94 & 21.67 & 29 & 19.33 \\
\hline$(8)$ & 30 & 20 & 94 & 62.67 & 22 & 14.67 \\
\hline$(9)$ & 16 & 10.67 & 68 & 45.33 & 41 & 27.33 \\
\hline$(10)$ & 8 & 5.33 & 66 & 44 & 57 & 38 \\
\hline
\end{tabular}

a. "Strongly agree (SA)"; "Agree $(A)$ "; "Neutral $(N)$ "; " "Disagree $(D A)$ "; "Strongly disagree (SDA)".

Table 3. Descriptions of Student VC Experience (Cont.)

\begin{tabular}{|c|ccc|cc|}
\hline \multirow{2}{*}{ Items } & \multicolumn{2}{|c|}{ DA $^{\mathbf{a}}$} & \multicolumn{2}{|c|}{ SDA $^{\mathbf{a}}$} \\
\cline { 2 - 5 } & Count & $\boldsymbol{\%}$ & Count & \% \\
\hline$(1)$ & 9 & 6 & 1 & 0.67 \\
\hline$(2)$ & 12 & 8 & 1 & 0.67 \\
\hline$(3)$ & 13 & 8.67 & 2 & 1.33 \\
\hline$(4)$ & 4 & 2.67 & 0 & 0 \\
\hline$(5)$ & 34 & 22.67 & 5 & 3.33 \\
\hline$(6)$ & 50 & 33.33 & 9 & 6 \\
\hline$(7)$ & 4 & 2.67 & 2 & 1.33 \\
\hline$(8)$ & 4 & 2.67 & 0 & 0 \\
\hline$(9)$ & 17 & 11.33 & 8 & 5.33 \\
\hline$(10)$ & 15 & 10 & 4 & 2.67 \\
\hline
\end{tabular}

\section{CONCLUSION AND IMPLICATIONS}

This research investigates the major problems with online platforms relevant to e-learning, and studies on the experience as well as effects of virtual classroom in higher education mainly from the perspectives of Chinese undergraduates. Results show that there exists a difference in terms of teaching quality between different teaching and learning patters. In our case, the rank of preference to learning environments is face-to-face format, followed by the blended approach and virtual classroom. Concerning the experience of using virtual classroom as indicated in table 1 of survey 2 , only $49 \%$ students agreed that they are 
satisfied with the usage of virtual classroom, and on the order of $13 \%$ students were dissatisfied with virtual classroom even though there are no other better alternatives in the early stage of COVID-19 crisis. As to the learning outcomes relevant to microeconomics course, the overall effect is lower than expected when compared with those prior to the pandemic.

This research has particular significance to classroom teachers as well as administrators in higher education institutions under the ongoing COVID-19 pandemic. Take the case of higher education in China as an example, in the spring of 2020, the Ministry of Education called for all colleges and universities to adopt the policy of "nonstop teaching and learning" which generated the timely online school opening across Chinese[6]. Thanks to this policy, otherwise the undergraduate students would suffer from the disruption of the pandemic.

At present, however, several Chinese cities are suffering from the new wave of COVID-19 due to the variation of the virus. In this circumstances, almost all schools including colleges and universities are forced to shift to virtual classrooms again. Even though there are some disadvantages in terms of virtual classroom when compared to those face-to-face physical classroom, there are no other better alternatives. Fortunately, after experiencing the online teaching and learning in the spring festival of 2020, both instructors and students are more experienced with adapting to the e-learning environment. And the distance teaching and learning will come to an end after all. As to the remaining higher education institutions beyond Fujian province, they have generally returned to traditional classroom teaching and learning, and a series of control and prevention countermeasures in coping with the pandemic such as staggered shift in having class is made on the basis of the specific situations in colleges and universities.

\section{ACKNOWLEDGMENT}

This paper is funded by Qingdao University of Technology: the program (F2019-002) is entitled Speciality Construction of Key Course Cluster of Economics.

\section{REFERENCES}

[1]Relan, A., and Gillani, B. B. "Web-Based Instruction and the Traditional Classroom: Similarities and Differences," In Khan, B. (Ed.), Web-based instruction. New Jersey: Educational Technology Publications, 1997, pp.25-37.

[2]Rockinson-Szapkiw, A. J., and Walker, V. L. "Web 2.0 technologies: facilitating interaction in an online human services counseling skills course," J. Technol. Human Services, vol. 27, 2009, pp. 175-193. DOI: https://doi.org/10.1080/15228830903093031

[3]Martin, F., and Parker, M. A. "Use of synchronous virtual classrooms: why, who, and how? MERLOT J. Online Learn. \& Teach.," vol.10, 2014, pp.192-210.

[4]Morrow, J., Phillips, D. J., and Bethune, E. "Teaching and learning: flexible modes and technology applications," Bri. J. Midwifery, vol. 15, 2007, PP.445448.DOI:https://doi.org/10.12968/bjom.2007.15.7.2379 9

[5] Clason, D. L. , \& Dormody, T. J. Analyzing data measured by individual likert-type items. Journal of Agricultural Education, vol.35, 1994, pp.31-35.DOI: https://doi.org/ 10.5032/jae.1994.04031

[6] Bao. Wei, "COVID-19 and online teaching in higher education: A case study of Peking University," Hum Behav \& Emerg Teaching. 2020;1-3. DOI: https://doi.org/10.1002/hbe2.191 